\title{
IDENTIFICAÇÃO PRELIMINAR DE ALGUMAS ESPÉCIES DO GÊNERO Candida spp. EM MEIO CROMÓGENO: RESULTADOS DE DOIS ANOS DE UM ESTUDO MULTICÊNTRICO REALIZADO NO CEARÁ
}

\author{
Everardo Albuquerque Menezes, ${ }^{1}$ Maria da Conceição dos Santos Oliveira Cunha ${ }^{2}$ \\ e Francisco Afrânio Cunha ${ }^{2}$
}

\section{RESUMO}

Candidemia é a quarta infecção sanguínea mais importante, sendo Candida albicans a espécie mais comumente isolada. Este estudo teve como objetivos identificar Candida spp. utilizando o meio CHROMagar ${ }^{\circledR}$ Candida e comparar com a identificação por microcultivo. Um total de 295 leveduras foram isoladas de sangue e urina de pacientes atendidos no Ceará, coletadas entre 2007 e 2009. As cepas foram semeadas em CHROMagar ${ }^{\circledR}$ Candida e as placas foram incubadas a $37^{\circ} \mathrm{C}$ por 24 a 72 horas antes da análise. Depois uma colônia foi transferida para o meio ágar arroz tween 80 , as placas foram incubadas por 24 a 72 horas a $25^{\circ} \mathrm{C}$ e, após o crescimento, examinadas microscopicamente. As espécies identificadas foram C. albicans (129), C. tropicalis (106), $C$. parapsilosis (20), C. krusei (5) e Candida spp. (35). O CHROMagar $($ Candida mostrou excelente concordância com o microcultivo e pode ser utilizado na identificação presuntiva de Candida spp.

DESCRITORES: Candidemia. Chromagar Candida. Candida spp.

\section{ABSTRACT}

Preliminary identification of some species of the genus Candida spp. on chromogenic medium: results of a 2-year multicentre study in Ceará, Brazil

Candidemia is the fourth most common bloodstream infection, with Candida albicans being the most common causative species. The purpose of this study was to identify Candida spp. on CHROMagar ${ }^{\circledR}$ Candida medium and compare it to microculture. A total of 295 yeast isolates of patients treated in Ceará were collected between 2007 and 2009 from blood and urine. All clinical specimens were analyzed by parallel cultivation on 2\% Potato-Dextrose agar, and on CHROMagar ( Candida. The isolates were identified on CHROMagar ${ }^{\circledR}$ Candida. The plates were incubated at

1 Departamento de Análises Clínicas e Toxicológicas da Faculdade de Farmácia Odontologia e Enfermagem da Universidade Federal do Ceará (DACT/FFOE/UFC).

2 Acadêmicos de Enfermagem da FFOE/UFC.

Endereço para correspondência: Everardo Albuquerque Menezes. Laboratório de Microbiologia de Leveduras. Rua Capitão Francisco Pedro 1210, Rodolfo Teófilo, CEP-60.420-970, Fortaleza, Ceará, Brasil. E-mail: menezes@ufc.br

Recebido para publicação em: 3/10/2011. Revisto em: 28/10/2011. Aceito em: 13/11/2011. 
$37^{\circ} \mathrm{C}$ for $24-72$ hours. After that, one colony was transferred onto a rice-agar plate and a cover slip was put on top of the smeared cells, the plates were incubated for $24-72$ hours at $25^{\circ} \mathrm{C}$. The colonies were then observed microscopically. The strains identified were C. albicans (129), C. tropicalis (106), C. parapsilosis (20), C. krusei (5) and Candida spp. (35). The CHROMagar ${ }^{\circledR}$ Candida showed excellent results and may be used as media for the detection of Candida spp.

KEY WORDS: Candidemia. Chromagar Candida. Candida spp.

\section{INTRODUÇÃO}

Nas últimas décadas, Candida spp. vem se tornando um importante agente causador de infecções. Os procedimentos médicos invasivos, doenças e medicamentos que comprometem o sistema imune e o fenômeno da resistência contribuem de forma decisiva para esse quadro (Gomes et al., 2010). Candidemia é a quarta infecção mais comum nos Estados Unidos e sua incidência está aumentando entre os pacientes imunocomprometidos (Zaas et al., 2010). Candida albicans causa entre $50 \%$ e $60 \%$ de todas as candidemias diagnosticadas, seguida de C. parapsilosis (10\% a 20\%) e C. tropicalis (6\% a 7\%). Infecções da corrente sanguínea por Candida spp. apresentam mortalidade elevada e são responsáveis pelo aumento dos custos hospitalares (Alfonso et al., 2010).

A mudança na epidemiologia das espécies de Candida e a disponibilidade de novas drogas antifúngicas tornaram necessária a identificação das leveduras segundo sua espécie (Murray et al., 2005).

Os isolamentos primários de leveduras de amostras clínicas são realizados em meio ágar Sabouraud glucose, o qual não permite a identificação das espécies. A identificação é realizada por uma série de testes adicionais que envolvem fermentação e assimilação de açúcares e os resultados podem levar vários dias. A utilização de meios cromógenos disponíveis pode ajudar a reduzir o tempo para isolamento, além de detectar a presença de culturas mistas (Eraso et al., 2006; Gaschet et al., 2008).

CHROMagar Candida ${ }^{\circledR}$ é um meio seletivo e diferencial utilizado para rápida purificação e diferenciação de espécies de Candida isoladas de amostras clínicas. Este meio especial contém substratos cromógenos que são transformados pelas enzimas das leveduras produzindo pigmentos específicos das espécies. A diferenciação das espécies é baseada na coloração e na morfologia. A incorporação de substratos cromógenos foi um grande avanço na identificação laboratorial de leveduras, pois eles permitem observar se a amostra clínica possui mais de uma levedura, possibilitam a identificação preventiva e direcionam a escolha do tratamento antifúngico a ser estabelecido (Sivakumar et al., 2009; Alfonso et al., 2010).

Este estudo avaliou a utilidade do meio cromógeno CHROMagar ${ }^{\circledR}$ Candida (Himedia- Mumbai, India) na identificação de cepas de Candida spp. isoladas de amostras clínicas provenientes de diversos centros de saúde no estado do Ceará, no período de dezembro de 2007 a dezembro de 2009. 


\section{MATERIAL E MÉTODOS}

Origem das cepas de Candida spp.

Foram utilizadas neste estudo 295 amostras de Candida spp. isoladas de amostras clínicas provenientes dos seguintes hospitais do Ceará: Hospital de Messejana (HM), Hospital Geral de Fortaleza (HGF), Hospital de Maracanaú (HMa), Hospital São José (HSJ), Laboratório Central de Saúde Pública do Ceará (LACEN), Hospital Regional de Iguatu (HRI) e Hospital Municipal de Russas (HMR).

Identificação presuntiva de Candida spp

Amostras clínicas foram inicialmente cultivadas em meio ágar batata dextrose com o intuito de verificar a presença de leveduras nestas amostras. Foram colocadas em estufa a $35^{\circ} \mathrm{C}$ por um período de até 72 horas. As amostras que cresceram em ágar batata dextrose foram novamente semeadas no mesmo meio de cultura para garantir a pureza das cepas. As cepas sugestivas de Candida spp. foram observadas em preparação lâmina-lamínula azul de algodão em objetiva de 40X (Menezes et al., 2009).

Após a confirmação, as cepas purificadas foram semeadas em meio CHROMagar Candida ${ }^{\circledR}$ (Himédia-Mumbai-Índia). Estas, então, foram colocadas em estufa a $35^{\circ} \mathrm{C}$ por um período de 48 horas, conforme instruções do fabricante, e, após esse período, verificou-se o crescimento. A correta identificação foi realizada de acordo com o manual do meio e foi verificada duas vezes em dias consecutivos para evitar erros (Gomes et al., 2010; Menezes et al., 2007).

Confirmação das cepas de Candida spp

Para a confirmação das cepas de Candida spp., foi realizado o microcultivo em ágar arroz. As lâminas com o microcultivo foram colocadas em estufa a $25^{\circ} \mathrm{C}$ por um período de 72 horas, tempo necessário para um crescimento adequado. Após esse período, foram observadas as características micromorfológicas que identificam cada espécie no microscópio ótico com objetiva 40X (Menezes et al., 2007).

Os isolados identificados no CHROMagar Candida ${ }^{\circledR}$ (HimédiaMumbai-Índia) e com micromorfologia compatível com C. albicans foram submetidos ao teste de produção de tubo germinativo. Todos os testes foram realizados em duas ocasiões diferentes e por executores diferentes. Em todas as etapas do estudo, foram utilizadas as cepas-padrão: Candida albicans ATCC 14053, Candida albicans ATCC 10231, Candida parapsilosis ATCC 22019 e Candida krusei ATCC 6920 (Menezes et al., 2007; Menezes et al., 2009; Gomes et al., 2010). 


\section{RESULTADOS}

Nesta pesquisa, foram isoladas e identificadas 295 cepas de Candida spp. de amostras biológicas de pacientes do Ceará, ocorrendo um predomínio de cepas não albicans (56,3\%). A epidemiologia das infecções por Candida spp. está mudando e, no Ceará, o fenômeno acompanha o que está ocorrendo no mundo inteiro (Horn et al., 2007; Lockhart et al., 2008; Pfaller et al., 2010), foram isoladas C. albicans em 42,7\% das amostras (Figura 1).

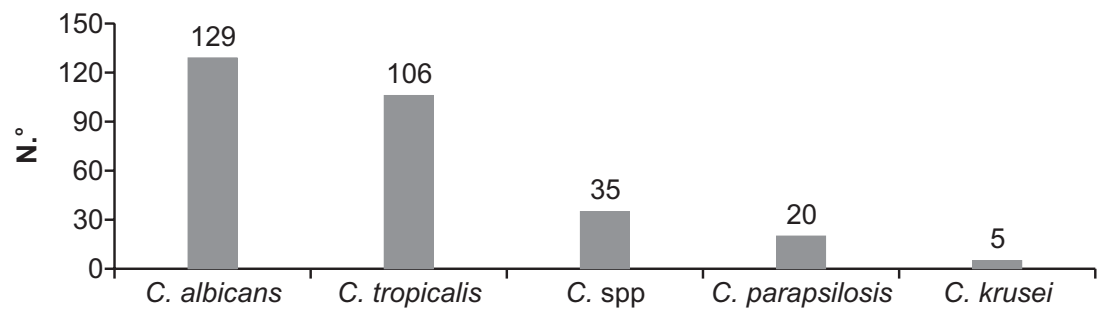

Figura 1. Cepas de Candida spp. isoladas no Ceará.

O meio cromógeno diminui o tempo de identificação de Candida e permite a rápida distinção entre as diversas cepas, sua limitação está no fato de somente identificar quatro das espécies patogênicas de Candida: C. albicans, que neste meio aparece como uma colônia verde; $C$. tropicalis, que tem uma coloração azul com o pigmento se difundindo para o meio; $C$. parapsilosis, que aparece como rosa-pálido e $C$. krusei, que pode ser vista como uma colônia rosa-escura em toda a superfície do meio. A Figura 2 mostra a identificação realizada em meio cromógeno.

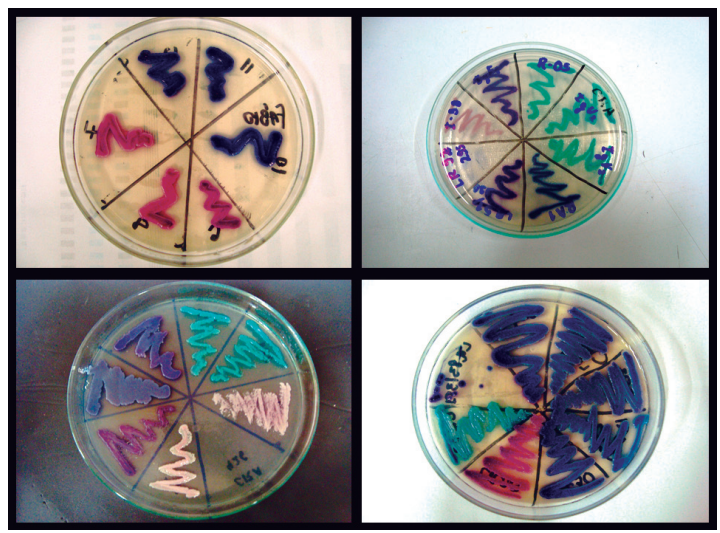

Figura 2. Identificação de cepas de Candida spp. isoladas em estudo multicêntrico realizado no estado do Ceará, entre 2007-2009. C. albicans - verde; $C$. tropicalis- azul. C.parapsilosis-rosa. 
Após a identificação sugestiva, a confirmação das principais espécies foi realizada pelo método do microcultivo, pois o principal objetivo era correlacionar a identificação por intermédio do meio cromógeno com a micromorfologia. As principais espécies patogênicas de Candida spp. tiveram sua micromorfologia compatível com a encontrada no meio CHROMagar Candida ${ }^{\circledR}$ (Quadro 1).

Quadro 1. Características macro e micro morfológicas de Candida spp nos meios CHROMagar Candida e ágar arroz + Tween 80.

\begin{tabular}{lll}
\hline \multicolumn{1}{c}{ Espécies } & \multicolumn{1}{c}{ CHROMagar Candida } & \multicolumn{1}{c}{ Agar Arroz + Tween 80 } \\
\hline Candida albicans & $\begin{array}{l}\text { Colônias verdes, } \\
\text { aparência distinta consistente }\end{array}$ & $\begin{array}{l}\text { Clamidósporos presentes, pseudohifas } \\
\text { abundantes, algumas hifas verdadeiras, grupos } \\
\text { de blastosporos ao longo das pseudohifas }\end{array}$ \\
\hline Candida tropicalis & $\begin{array}{l}\text { Colônias azul metálico, } \\
\text { com pigmento metálico se } \\
\text { difundindo para o meio }\end{array}$ & $\begin{array}{l}\text { Pseudohifas abundantes muitas vezes } \\
\text { irradiando com grupos de blastoconídeos no } \\
\text { centro; aparência variável }\end{array}$ \\
\hline Candida krusei & $\begin{array}{l}\text { Colônias grandes, } \\
\text { rosa planas, superfície fosca }\end{array}$ & $\begin{array}{l}\text { Pseudomicélio extenso e ramificado com } \\
\text { cadeias de células alongadas dando uma } \\
\text { aparencia de árvore; grupos e cadeias de } \\
\text { blastosporos ao longo das pseudohifas }\end{array}$ \\
\hline Candida parapsilosis & $\begin{array}{l}\text { Colônias rosa-amarelada a } \\
\text { rosa pálido, aparência variável }\end{array}$ & $\begin{array}{l}\text { Cadeias ramificadas de células alongadas com } \\
\text { grupos de blastosporos ao longo delas; células- } \\
\text { gigantes ocasionais; aparência variável }\end{array}$ \\
\hline
\end{tabular}

\section{DISCUSSÃO E CONCLUSÕES}

Os meios cromógenos para identificação de Candida spp. estão disponíveis desde 2002. Eles facilitam o trabalho uma vez que podem ser utilizados na identificação presuntiva diminuindo, assim, o tempo de identificação e possibilitam a orientação da terapêutica correta (Araújo et al., 2005; Gaschet et al., 2008).

A capacidade de identificação do meio cromógeno foi comparada com um método molecular, sendo utilizados 52 isolados clínicos de Candida spp. Das amostras testadas, $65,4 \%$ apresentaram resultados semelhantes pelos dois métodos, $23,1 \%$ apresentaram resultados discrepantes e $11,5 \%$ das cepas não puderam ser identificadas (Oliveira et al., 2006). Neste estudo, as cepas de C. albicans ( $=129)$, C. krusei (n = 5), C. tropicalis (109) e C. parapsilosis (20), foram identificadas e confirmadas pela utilização de meio cromógeno e micromorfologia.

$\mathrm{O}$ meio CC pode ser útil na diferenciação de $C$. albicans e $C$. dubliniensis, pois fornece tonalidades levemente diferentes da cor verde, no entanto são necessários outros testes fenotípicos e moleculares para distinguir as duas espécies. C. dubliniensis produz mais clamidoconídeos que C. albicans (Álvarez et al., 2007). Nesta pesquisa não foram diferenciadas as duas espécies, todas foram identificadas como C. albicans. 
Trabalhos científicos relatam que a identificação de $C$. parapsilosis utilizando meio $\mathrm{CC}$ pode ser difícil e muitas vezes leva a resultados duvidosos (Shawn et al., 2008). C. parapsilosis e Candida sp. apresentam dificuldades no momento da identificação, portanto a confirmação ocorre com o microcultivo. De acordo com os resultados aqui encontrados, foram identificadas 20 cepas de C. parapsilosis, no entanto para 35 cepas de Candida spp. não foi possível a identificação de sua espécie (Figura 1).

Pesquisadores que compararam o meio $\mathrm{CC}$ com a técnica molecular de PCR avaliaram sensibilidade e especificidade do meio CC, encontrando os seguintes resultados: para C. albicans foi de $97,9 \%$ e $83,3 \%$, respectivamente, e para C. tropicalis foi de 66,7\%, e 100\%, respectivamente (Martins et al., 2010). Cepas de Candida spp. provenientes de amostras de urina foram identificadas facilmente utilizando-se meio CC, o que demonstra sua utilidade no Laboratório de Análises Clínicas (Gomes et al., 2010; Menezes et al., 2009). Em uma pesquisa com 893 amostras de urina, semeadas diretamente em meio cromógeno, foi possível isolar e identificar 104 cepas de Candida spp, o meio mostrou-se útil na cultura direta de urina (Okulicz et al., 2007).

Como já foi referido, o uso de meios cromógenos na rotina laboratorial facilita a identificação presuntiva e ajuda na escolha correta da terapêutica, além disso, acelera a liberação dos resultados dos exames (Alfonso et al., 2010), portanto esses meios estão sendo desenvolvidos e utilizados em diversos países do mundo, seus componentes são diferentes e as cores produzidas pelas cepas podem variar. Todos os meios cromógenos disponíveis são capazes de distinguir cepas de $C$. albicans de Candida não albicans, o que demonstra sua importância. Testes com um grande número de espécies devem ser realizados para validar esses meios (Sivakumar et al., 2009; Weissenbacher et al., 2009).

Em resumo, o meio $\mathrm{CC}$ é extremamente útil na rápida identificação de cepas de Candida spp. No estado do Ceará, as principais cepas encontradas foram C. albicans e C. tropicalis, que são facilmente diferenciadas pelo meio CC, método valioso para a rotina laboratorial. A identificação de $C$. parapsilosis necessita da confirmação pela técnica de microcultivo.

\section{AGRADECIMENTOS}

Projeto Financiado pelo Conselho Nacional de Desenvolvimento Científico e Tecnológico (CNPq). Processo. 473417/2007.

\section{REFERÊNCIAS}

1. Alfonso C, López M, Arechavala A, Perrone MC, Guelfand L, Bianchi M. Identificación presuntiva de Candida spp. y de otras levaduras de importância clínica: utilidad de Brilliance Candida Agar. Rev Iberoam Micol 27: 90-93, 2010.

2. Álvarez MI, Suárez BL, Caicedo LD. Isolation of Candida dubliniensis for the first time in Cali, Colombia, and its Identification with Phenotyping Methods. Mycopathologia 167: 19-24, 2007. 
3. Araujo CR, Miranda KC, Passos XS, Souza LKH, Lemos JA, Khrais CHA, Costa CR, Silva MRR, Fernandes OFL. Identificação das leveduras do gênero Candida por métodos naturais convencionais e pelo método cromógeno CHROMagar Candida. Rev Patol Trop 34: 37-42, 2005.

4. Eraso E, Moraguez MD, Vidal MV, Sahand IH, Gómez NG, Pontón J, Quindós G. Evaluation of the new chromogenic medium Candida ID 2 for isolation and identification of Candida albicans and other medically important Candida species. J Clin Microbiol 44: 3340-3345, 2006.

5. Gaschet A, L'ollivier C, Laplanche A, Vagner O, Dalle F, Cuisenier B, Valot S, Bonnin A. Evaluation of CandiSelect4, a new chromogenic medium for isolation and presumptive identification of Candida species from clinical specimens. J Mycol Med 18: 89-95, 2008.

6. Gomes CL, Cavalcante JE, Cunha FA, Amorim LN, Menezes EA. Identificação e perfil de sensibilidade de Candida spp. isoladas de urina de pacientes com candidúria em Iguatu-Ceará. Rev Bras Anal Clin 42: 223-225, 2010.

7. Horn D, Neofytos D, Fishman J, Steinbach W, Anaisie E, Marr KA, Pfaller MA, Olyaei A. Use of the PATH Alliance database to measure adherence to IDSA guidelines for the therapy of candidemia. Eur J Clin Microbiol Infect Dis 26: 907-914, 2007.

8. Lockhart SR, Messer SA, Pfaller MA, Diekema DJ. Geographic Distribution and Antifungal Susceptibility of the Newly Described Species Candida orthopsilosis and Candida metapsilosis in Comparison to the Closely Related Species Candida parapsilosis. J Clin Microbiol 46: 2659-2664, 2008.

9. Martins M, Henriques M, Ribeiro AP, Fernandes R, Gonçalves V, Seabra A, Azeredo J, Oliveira R. Oral Candida carriage of patients attending a dental clinic in Braga, Portugal. Rev Iberoam Micol 27: 119-124, 2010.

10. Menezes EA, Lustosa AK, Freire CCF, Cunha FA, Montenegro RM, Montenegro Júnior RM. Frequência e atividade enzimática de Candida spp. na cavidade oral de pacientes diabéticos do serviço de endocrinologia de um hospital de Fortaleza-CE. J Bras Patol Med Lab 43: 241-244, 2007.

11. Menezes EA, Mendes LG, Cunha FA. Resistência a antifúngicos de Candida tropicalis isoladas no Estado Ceará. Rev Soc Bras Med Trop 42: 354-355, 2009.

12. Murray CK, Beckius ML, Green JA, Hospenthal DR. Use of chromogenic medium in the isolation of yeasts from clinical specimens. J Med Microbiol 54: 981-985, 2005.

13. Pfaller MA, Castanheira M, Messer SA, Moet GJ, Jones RN. Variation in Candida spp. distribution and antifungal resistance rates among bloodstream infection isolates by patient age: report from the SENTRY Antimicrobial Surveillance Program (2008-2009). Diagn Microbiol Infect Dis 68: 278-283, 2010.

14. Okulicz JF, Rivard RG, Conger NG, Nguyen MX, Hospenthal DR. Primary isolation of Candida species from urine specimens using chromogenic medium. Mycoses 51: 141-146, 2007.

15. Oliveira NC, Rampazzo RCP, Minari MC, Corrêa PRC, Bizerra FC, Carneiro M, Svidzinski TIE, Maia LC, Yamada-Ogatta SF. Utilização de um meio cromogênico e da técnica de semi-nested PCR para identificação de espécies de Candida. Semina: Cienc Biol Saude 27: 125-132, 2006.

16. Shawn R, Lockhart SR, Messer SA, Pfaller MA, Diekema DJ. Lodderomyces elongisporus Masquerading as Candida parapsilosis Cause of Bloodstream Infections. J Clin Microbiol 46: 374-376, 2008.

17. Sivakumar VG, Shankar P, Nalina K, Menon T. Use of CHROMagar in the Differentiation of Common Species of Candida. Mycopathologia 167: 47-49, 2009.

18. Weissenbacher T, Witkin SS, Ledger WJ, Tolbert J, Gingelmaier A, Scholz C, Weissenbacher ER, Friese K, Mylonas I. Relationship between clinical diagnosis of recurrent vulvovaginal candidiasis and detection of Candida species by culture and polymerase chain reaction. Arch Gynecol Obstet 279: 125-129, 2009.

19. Zaas AK, Aziz H, Lucas J, Perfect Jr, Ginsburg GS. Blood Gene Expression Signatures Predict invasive candidiasis. Sci Transl Med 2: 1-10, 2010. 